\title{
Refining national culture and entrepreneurship: the role of subcultural variation
}

\author{
Dave Valliere
}

Correspondence: valliere@ryerson.ca Ted Rogers School of Management, Ryerson University, 350 Victoria St, Toronto, Ontario M5B 2K3, Canada

\begin{abstract}
This study investigates attitudes towards entrepreneurship within a national culture. The effects of culture represent the most significant and unexplored factor in current theories of entrepreneurial intentions. The study uses $Q$ methodology to conduct a hybrid qualitative and quantitative exploration of the attitudes about entrepreneurship that are present within the cultural discourse. Within one region of Canada, three distinct viewpoints are discovered which share many attitudes about entrepreneurship, but which also feature clear differences in their potential to positively or negative influence beliefs and attitudes of individuals. This study contributes to a theory by demonstrating that culture is multidimensional and heterogeneous in the way that broad constructs of "national culture" are translated into influences on individual traits and characteristics.
\end{abstract}

Keywords: Entrepreneurial intent, Culture, Subjective norms, Theory of planned behaviour, Q methodology

\section{Introduction}

The social impact of entrepreneurship has been repeatedly seen to depend on objective characteristics of a country, such as the resource endowments, institutions, and overall wealth of a society (Valliere \& Peterson, 2009; Wong, Ho, \& Autio, 2005). This relationship similarly holds for individual regions or clusters within a single country (Armington \& Acs, 2002; Davidsson, 1995; Rocha \& Sternberg, 2005). Within Canada, significant differences in entrepreneurship levels can be observed among regions and communities (Davis, Valliere, Lin, \& Wolff, 2014; Langford, Josty, \& Holbrook, 2013). These differences partly reflect regional differences in the objective social and economic conditions of these regions, such as populations, economic output, education levels, $R \& D$ investments, and the like.

But differences in entrepreneurship can also be seen in countries and regions with very similar objective circumstances. For example, Netherlands and Germany have very similar objective institutions (for example, educational and legal systems) and economies (for example, per capita GDP). But the Global Entrepreneurship Monitor reports the rate of "total entrepreneurial activity" in Netherlands as almost twice that in Germany (9.3\% vs. 5.0\%) (Amoros \& Bosma, 2013). Such differences cannot be fully explained by small differences in objective

(c) The Author(s). 2019 Open Access This article is distributed under the terms of the Creative Commons Attribution 4.0 International License (http://creativecommons.org/licenses/by/4.0/), which permits unrestricted use, distribution, and reproduction in any medium provided you give appropriate credit to the original author(s) and the source, provide a link to the Creative Commons license, and indicate if changes were made. 
circumstances. Subjective factors, such as connections between entrepreneurship and the social context (Bonaventura \& Caserta, 2012; Lyons, Alter, Audretsch, \& Augustine, 2012), may be exerting significant additional influence.

In general, these subjective factors influence the sense and meaning that individuals get from their objective surroundings-their ability to assess any opportunities and available resources that may support or inhibit entrepreneurship. Individuals choose to pursue entrepreneurial actions in a broad, socially constructed context that gives their actions meaning. This cultural context can differ widely among societies with very similar objective circumstances, by influencing the nature of supporting institutions (Heilbrunn, Itzkovitch, \& Weinberg, 2017; Ogunsade \& Obembe, 2016).

What these very different cultural cues illustrate is that objective opportunities and resources alone are not enough to create greater entrepreneurship within a society. The cultural factors that create subjective meaning for entrepreneurial actions must also be supportive. Clearly, subjective culture also matters to entrepreneurship.

\section{Literature of culture and entrepreneurship}

Much of the earliest research into culture and entrepreneurship adopted the national culture perspective of Hofstede (1980). From this perspective, culture is conceptualized as a monolithic property of nations that comprises power distance, individualism, masculinity, uncertainty avoidance, and long-term orientation. This framework of national culture dimensions was later expanded by the GLOBE project (House, Javidan, \& Dorfman, 2001) and by Hofstede himself, who added dimensions related to indulgence and monumentalism (Hofstede, Hofstede, Minkov, \& Vinken, 2008). There are many other theoretical perspectives on culture that may be relevant to the influences of society on individuals engaged in entrepreneurship, such as social entrepreneurship and Durkheim's problematisation of business ethics within a culture, the structural iconoclasm of entrepreneurs under conflict theory, their permitted deviance within institutional fields that compete with culture, and their capabilities in reconceptualization of opportunities and resources in the postmodern view (Giddens, 1971; Lehman \& Young, 1974; North, 1991; Valliere \& Gegenhuber, 2014). Many of these remain unexplored avenues as, to date, the Hofstede conception of a national culture has continued to dominate research into the entrepreneurial prevalence of individuals (e.g., Autio, Pathak, \& Wennberg, 2013; Hayton, George, \& Zahra, 2002; McGrath, MacMillan, \& Scheinberg, 1992; Siu \& Lo, 2013).

Numerous entrepreneurship researchers have tried to establish links between Hofstede's dimensions of national culture and the prevalence of entrepreneurial activities, such as by arguing that a culture that has low avoidance of uncertainty would be more likely to support the risk-taking inherent in entrepreneurial new venture development (McGrath et al., 1992; Swierczek \& Ha, 2003). Similarly, it has been argued that individualist cultures promote the vision and bold action necessary to embark on entrepreneurship and that collectivist cultures promote the unity of action and resource investment necessary to sustain new entrepreneurial ventures, and thus, cultures with a balance of these two characteristics will be the most entrepreneurial (Morris, Avila, \& Allen, 1993). But many of the early findings from this first research stream had low explanatory power or poor replicability, especially when other potential sources of 
variance were adequately controlled, and have not been found to generalize across very different cultures or levels of economic development (Pinillos \& Reyes, 2011; Siu \& Lo, 2013). Moreover, the effects of individualism/collectivism and of uncertainty avoidance in a national culture seem to operate differently on specific aspects of the entrepreneurial function (Ibrahim, Devesh, \& Ubaibullah, 2017). For example, Autio et al. (2013) found that a collectivist culture has a negative influence on entrepreneurial entry, but a positive influence on entrepreneurial growth aspirations.

A second approach to understanding social and cultural influences on entrepreneurship focused attention on the individual and the micro culture of their immediate surroundings. Attempts have been made to predict entrepreneurship from such individual-level characteristics as gender and family history (Carr \& Sequeira, 2007; Drennan, Kennedy, \& Renfrow, 2005), education (Peterman \& Kennedy, 2003), personality traits (Zhao, Seibert, \& Lumpkin, 2010), and cognitive traits such as overconfidence (Bernardo \& Welch, 2001) or risk attitudes (Palich \& Bagby, 1995; Simon, Houghton, \& Aquino, 1999). This approach argues that, within ethno-cultural or demographic subgroups, cultural factors influence the perceptions an individual has about broader social norms and the specific desirability of entrepreneurship (Urban \& Ratsimanetrimanana, 2015). While this approach has led to the discovery of some idiosyncratic correlations between these selected characteristics, it suffers from a lack of a unifying overall theoretical framework that contextualizes culture and that links the disparate findings.

A third approach has adopted a cognitive perspective based in Ajzen's Theory of Planned Behaviour (TPB) (Ajzen, 1991) and Shapero's Entrepreneurial Event model (Shapero \& Sokol, 1982). An important integration of these perspectives was recently developed by Schlaegel and Koenig (2014), wherein entrepreneurial intent is a direct consequence of elements of Shapero's Entrepreneurial Event model (the perceived desirability and perceived feasibility of entrepreneurship), and these are themselves consequences of elements from TPB (attitudes, subjective norms, self-efficacy, and perceived behavioural control). Their test of this integrated model showed that the influence of TPB elements and perceived feasibility is significantly mediated by the perceived desirability of entrepreneurship. This is to say, "It is an individual's desire through which the other determinants are transformed" (p. 317), and this desire is shaped by social and cultural forces. Under the right triggering conditions, it can be transformed into actual behaviours (Schlaegel, Engle, Dimitriadi, \& Taureck, 2015).

In $\mathrm{TPB}$, a subjective norm is "the perceived social pressure to perform or not to perform the behavior" in question (Ajzen, 1991: 188), where social pressure is understood to be a manifestation of culture. On this basis, some researchers are now investigating both the embodiment of cultural factors in the subjective norm construct of the model, and the potential moderating effects of cultural factors on various linkages within the model (e.g., Barazandeh, Parvizian, Alizadeh, \& Khosravi, 2015; Grunhagen \& Volkmann, 2014; Semerci \& Cimen, 2017; Zhang, Wang, \& Owen, 2015). Following the work of Liñán and Chen (2009) on the potential moderation role of culture, Siu and Lo (2013) have argued that the degree of individualism or collectivism in the national culture (as conceived by Hofstede) would manifest as a construal of self that would moderate the relationships from personal attitudes, social norms, and self-efficacy to the 
resulting entrepreneurial intent. They hypothesised that in a collectivist culture, selfconstrual would be highly interdependent and this would strengthen the influence of social norms on entrepreneurship while also weakening the influence of personal attitudes and self-efficacy. Their empirical testing found the expected moderation of the influence of social norms, but not the others. Other researchers have found suggestions that specific cultural content also operates on the construction of an entrepreneurial self-identity and thereby on entrepreneurial intentions (Kauppinen, 2017).

But this research approach faces a daunting level-crossing challenge in bridging from the macro-level factors of Hofstede's national culture constructs to the micro-level cognitions of individuals. Entrepreneurship research using this conception assumes cultures are homogeneous within nations and that all individuals, as situated actors within the culture, enact the same cultural roles and meanings. It does not admit a possible plurality of interpretations of culture and a corresponding plurality of beliefs, attitudes, and perceptions of social norms.

In addition to these three objectivist approaches to the influence of culture on entrepreneurship, a broad subjectivist stream of research has developed to highlight the importance of individual sense-making and personal meaning in the motivation of entrepreneurial behaviours. To the extent that culture is the social construction of shared meanings through myths and metaphors, it must influence entrepreneurship by enacting the role of entrepreneurs as sense-makers and storytellers (Drakopoulou-Dodd, 2002; Nicholson \& Anderson, 2005). Through this approach it is possible, for example, to gain an improved understanding of entrepreneurship by examining the imagery and metaphors by which a culture views entrepreneurs as explorers, fighters, game players, actors, creators, nurturers, or producers (Anderson, 2005; Cardon, Zietsma, Saparito, Matherne, \& Davis, 2004; Hyrsky, 1999; Pitt, 1998). Very recent research highlights the importance of individual cultural orientation and cultural intelligence in interpreting broad cultural cues in an entrepreneurship context (Balaku, Kikooma, Bantu, Onderi, \& Otto, 2019).

These examples illustrate the importance of shared meaning and cultural sanction in establishing the legitimacy of entrepreneurial roles within a specific social context (Huggins \& Thompson, 2012; MacIntosh \& Scapens, 1990). This relationship between subjective interpretation and career activities echoes Weber's earlier narrow example of how subjective meaning derived from the Protestant work ethic formed the foundation for the capitalist system in Europe and North America, one which legitimized entrepreneurial activity by stigmatizing idleness (Weber, 1905). Legitimacy is a status conferred by social actors when a legitimated organization exhibits values and actions that are considered to be valid, rational and reasonable, and aligned with those of the endorsing social actors. Actors within a cultural context are able to gain legitimacy by conforming to the formal and informal "rules of the game" (Baum \& Oliver, 1991; DiMaggio \& Powell, 1983). Legitimacy therefore leads to an increase in social profile, status, and cultural rewards for entrepreneurship. Legitimacy provides a stable basis for a prospective entrepreneur to justify and persist in the disruptive activities entailed in launching a new business (Anderson, Drakopoulou-Dodd, \& Scott, 2000; Gatewood, Shaver, \& Gartner, 1995). In many cultures, it is the subjective identity assumed by entrepreneurs that gives them the privilege to bring about the creative destruction of existing social institutions or to re-enact them within new perspectives (Anderson \& Warren, 2011). And it is the unique ability of entrepreneurs to create new subjective meanings from the existing objective conditions that underpins their source of value creation (Valliere, 2015; Valliere \& Gegenhuber, 2014). 
These diverse and independent approaches to cultural influence highlight a need for theoretical consolidation and integration. From an objectivist stance, there is an integration required to connect the macro-level perspective of Hofstede's national culture dimensions to the micro-level cognitions of individuals. From a subjectivist stance, there is a similar integration required to connect the macro-level shared myths and metaphors of society to the micro-level perceptions and self-construal of individuals. And there is a further need to integrate the objective and subjective perspectives to provide a holistic understanding of the different paths through which culture may influence entrepreneurship. Such integration of perspective may require a focus on the evaluation of current career state and the transition to a new state (Higgins, 2008).

It is likely that these integrations may occur at an intermediate level, where the generalizations of macro culture can be teased apart into more nuanced streams of influence and the idiosyncrasies of individuals can be abstracted into broader and theoretically relevant constructs. Lacking the theoretical perspective to link macro culture to individual influences, prior entrepreneurship researchers have typically reflected this effect by including as antecedents of entrepreneurship the possible influences of family and friends or the general prevalence of entrepreneurship in the individual's surrounding social milieu (Chrisman, Chua, \& Steier, 2002). What this suggests is that, while Hofstede's national culture undoubtedly has some effect on the beliefs, attitudes, and intentions of individuals relative to entrepreneurship, these macro influences are likely intermediated by a much stronger effect due to the immediate social relationships and networks in which the individual is embedded. It is this potential for the intermediated cultural influence that the present research aims to explore.

This effect should not be mistaken for regional variations in culture that affect regional levels of entrepreneurship. These regional cultures simply reflect the fact that the borders of "national" cultures do not mirror those of political "states"-national cultures may span smaller domains that the country in which they occur (for example, Quebec (Davis, 1988)) or may transcend individual countries (for example, expats and home-country nationals (Chu, 1996)). What is being suggested is the existence of variation within a single national entity, whether or not it corresponds to a single political state.

This intermediate culture has been given very little attention by entrepreneurship researchers to date. Little is known about the ways in which national culture factors manifest within smaller communities of opinion, and how these localized factors in turn influence individuals towards or away from entrepreneurship. For this reason, an exploratory study of culture should be performed within a single and controlled national cultural context, even if that requires sampling within only a single region of a country and not the entire country.

\section{Methods}

The present empirical study represents a step towards this goal by exploring the currents of opinion towards entrepreneurship that exist within the culture of Southern Ontario. It attempts to bridge between micro and macro levels by capturing nuanced perspectives at an individual level and then synthesizing these into broader and more general themes and constructs that can be situated within the national culture. 
This task calls for the analytical insights of both quantitative and qualitative research approaches. Quantitative methods can provide the power to precisely distil streams of commonality and significant difference that may exist within an overarching national culture, while qualitative methods can provide the deeper insights into the subjective meaning and influence of these streams on the entrepreneurial beliefs and attitudes of individuals. Such an integration of complementary quantitative and qualitative methodological stances in an exploratory context is a defining feature of Q methodology.

\section{Q methodology}

The Q methodology was developed by Stephenson $(1935,1953)$ to provide a systematic study of subjectivity and was specifically designed to analyse the nature and diversity of people's attitudes, perspectives, or subjective experiences relation to a given topic (Stephenson, 1953). This approach lends itself to research questions "that have many, potentially complex and often socially contested answers" (Stenner, Watts, \& Worrell, $2008,219)$, which aptly describes the range of potential perspectives about entrepreneurship that may exist within a national culture. $Q$ analysis provides information and insight about any similarities and differences in the viewpoints that may exist about the subject. The factors that emerge from $\mathrm{Q}$ analysis thus represent viewpoints or clusters of subjectivity that are functionally operant within a culture. This is to say, the results of $\mathrm{Q}$ describe a population of viewpoints that exist in the cultural discourse, not a population of people.

Q methodology has been used successfully to gain insight into the sociocultural dimensions of business from very many perspectives. These include a variety of public policy and health initiatives (De Mol \& Buysse, 2008; Janson, Militello, \& Kosine, 2008; Ockwell, 2008), marketing studies such as customer attitudes towards marketing promotions in the media industry (Michelle \& Davis, 2014) and customer attitudes towards social issue marketing campaigns (Gustafson, Hanley, \& Popovich, 2008), market acceptance of online trading innovations (Lee \& Synn, 2001), and market acceptance of technology innovations in the agricultural sector (Hermans, Kok, Beers, \& Veldkamp, 2012). Q has been comparatively little-used in studies of entrepreneurship to date, but it has brought some useful insights into subjective perspectives of the requisite capabilities of IT entrepreneurs (Chang, 2012) and attitudes towards risk perception and decision making by VCs in the post-bubble environment (Babcock-Lumish, 2005). But there do not appear to have yet been any studies that have applied Q methodology to the examination of the influences of culture and societal norms on entrepreneurship.

Briefly stated, with Q methodology a respondent is presented with a set of statements about the topic of interest, where these statements are matters of opinion, not simple facts. Respondents are asked to rank order them (strongly agree/disagree) in a particular fashion; this rank ordering process is what captures individual subjectivity, because the set of rank-ordered statements (a "Q-sort") implicitly represents the beliefs of that respondent. The collection of Q-sorts is then a factor analysed to identify streams of shared subjectivities in the population that correspond to the types of viewpoint that exist. The details of these methodology steps are more completely described below.

As an exploratory approach, the goal of Q methodology is to identify commonalities and differences in the viewpoints that are latent in a culture or society, not to measure 
the strength with which these viewpoints are held, nor the proportions in which they exist in the society. And it does so with greater systematic and methodological transparency than the more usual qualitative methods. The focus is on quality of insight, not quantity. Therefore, small but diverse samples are more important than large samples with high statistical power. An underlying presumption of $\mathrm{Q}$ is that only a limited number of distinct viewpoints exist on any topic. Therefore, any well-structured statement set (reflecting a wide range of existing opinions on the topic) administered to a diverse sample of respondents will reveal the existence of these viewpoints.

\section{Data source}

The first step in applying Q methodology to entrepreneurship is to create a set of statements that capture the range of discourse about entrepreneurship that exists within a culture, called the "concourse." Broadly, a concourse can be thought of as "the flow of communicability surrounding any topic [in] the ordinary conversation, commentary, and discourse of everyday life" (Brown, 1993). A concourse "consists of all that can be thought and said about a situation, event, or phenomenon" (Durning \& Brown, 2007). The objective of Q-methodology is to reveal the inherent structure of a concourse-the streams of thought that flow and contend within the cultural discourse.

In the present study, an initial concourse of 100 statements was produced from a broad review of published sources (for example, academic literature, business press, and popular discussion of entrepreneurship). The review sought to capture statements of extant opinion in several general categories: who they are (for example, "entrepreneurs are dreamers with high goals and aspirations"), what they do (for example, "entrepreneurs are like actors, telling a convincing story of a possible future"), where and when they do it (for example, "the best time to start a new business is when you are young"), why they do it (for example, "starting a business is more risky than working for someone else"), what they use (for example, "formal education is unimportant to becoming an entrepreneur"), and how they impact others (for example, "entrepreneurs are admired by others").

The next step in Q methodology is to select from the full concourse a subset of statements that will be rank ordered by the respondents, called the " $Q$ set." The $Q$ set is comprised solely of utterances which exist in the cultural discourse, and it is therefore indigenous to the understandings of people within that culture. The Q set should provide a miniature that, in all major respects, contains the comprehensiveness of the larger cultural discourse, but is a more manageable sorting task for the respondents to perform. One meta-review of studies utilizing Q methodology has observed Q sets ranging in size from 25 to 82 statements, with a mean of 41 (Dzopia \& Ahern, 2011). The creation of the Q set therefore requires some judgement on the part of the researchers and should include statements selected to be widely different from one another in order to make the Q set broadly representative of the concourse (Brown, 1980).

In the present study, a $Q$ set of 42 statements was created by eliminating from the concourse any statement with significant conceptual overlap or redundancy and by explicitly retaining statements to provide coverage of all of the general categories described above. Table 1 lists the statements of the $\mathrm{Q}$ set used in this study. These statements were printed onto the cards to be rank ordered by respondents. 
Table $1 \mathrm{Q}$ set statements

\begin{tabular}{|c|c|}
\hline Card number & Statement \\
\hline 1 & $\begin{array}{l}\text { Some social groups (class, religion, caste, ethnicity, gender) are better suited to become } \\
\text { entrepreneurs than others }\end{array}$ \\
\hline 2 & Some people and cultures are just more entrepreneurial than others \\
\hline 3 & There is a unique personality type suited to being an entrepreneur \\
\hline 4 & Entrepreneurs are more concerned with the Quantity of life than the Quality of life \\
\hline 5 & Entrepreneurs are unreasonable people who do not respect social rules \\
\hline 6 & Entrepreneurs are independent rebels who operate outside of regular society \\
\hline 7 & Entrepreneurs care more about the future possibilities than the present way things are \\
\hline 8 & Entrepreneurs see the world differently than other people \\
\hline 9 & You should not trust entrepreneurs, they will try to cheat you \\
\hline 10 & Entrepreneurs have unrealistically high opinions of themselves \\
\hline 11 & $\begin{array}{l}\text { If you know that something needs to be done in the world, you should do it yourself instead of } \\
\text { waiting for someone else to do it }\end{array}$ \\
\hline 12 & Entrepreneurs control their own destiny \\
\hline 13 & Entrepreneurs actually do the things that other people only dream about \\
\hline 14 & Entrepreneurs seek out problems and places of dissatisfaction in life \\
\hline 15 & Entrepreneurs are aggressive troublemakers who create problems \\
\hline 16 & Entrepreneurs exploit the work of others to make themselves rich \\
\hline 17 & Copying other successful businesses is a good idea \\
\hline 18 & You must be very lucky to succeed as an entrepreneur \\
\hline 19 & $\begin{array}{l}\text { Entrepreneurship is more about how you view the world and respond to opportunities than } \\
\text { managing a small business }\end{array}$ \\
\hline 20 & The purpose of entrepreneurship is to make lots of money \\
\hline 21 & The purpose of entrepreneurship is to satisfy the needs and desires of other people \\
\hline 22 & The purpose of entrepreneurship is to create jobs for others \\
\hline 23 & The purpose of entrepreneurship is personal independence and autonomy \\
\hline 24 & Entrepreneurs deserve to be rewarded for trying risky new things \\
\hline 25 & Entrepreneurs have a lot of freedom because they are not accountable to anyone else \\
\hline 26 & What you achieve in business in more important than what you must do to achieve it \\
\hline 27 & If you cannot find a job, you should create one on your own \\
\hline 28 & You need to have a lot of money before you can start a new business \\
\hline 29 & You need to be well-connected to powerful people to start a new business \\
\hline 30 & It is a good idea to use the money of other people (investors) to start your business \\
\hline 31 & The most important thing for starting a business is to spot a big customer need \\
\hline 32 & The most important thing for starting a business is to have talented partners \\
\hline 33 & The most important thing for starting a business is to invent a useful new product or service \\
\hline 34 & The support of friends and family is important when starting a new business \\
\hline 35 & Entrepreneurs make society better \\
\hline 36 & Entrepreneurs generate new wealth that spreads through society \\
\hline 37 & Entrepreneurs tend to divide people and disrupt society \\
\hline 38 & People who start new businesses and then fail are unreliable and not to be trusted \\
\hline 39 & Nothing good can come from trying to start a business but failing at it \\
\hline 40 & Entrepreneurs must be prepared to challenge the existing social structures \\
\hline 41 & $\begin{array}{l}\text { It is a bad thing when entrepreneurs destroy an old type of business or traditional way of doing } \\
\text { business }\end{array}$ \\
\hline 42 & Anyone can move up in society by being more entrepreneurial \\
\hline
\end{tabular}


The next step in the methodology is to select the participating respondents, sometimes referred to as the "P set." As mentioned above, it is not desired that the P set be large and randomized as with most statistical studies. Rather, it is desired that the P set be a sample of respondents who are theoretically relevant and may be expected to have clear and distinct viewpoints on entrepreneurship. Therefore, the researcher aims to select a sample of individuals who are likely to have quite different views from each other. Most Q studies have a few dozen respondents, although highly relevant results can be obtained with far fewer respondents if they are diverse (Watts \& Stenner, 2005). One meta-review observed a range of $\mathrm{P}$ set sizes of 20 to 103 respondents, with a mean of 36 (Dzopia \& Ahern, 2011). Ideally, the aim is to have four or five individuals representing each anticipated viewpoint that exists (of which there are often two to four and are rarely more than six). Larger datasets are not needed because the sampling process is of the operant viewpoints, not the respondents themselves (Stainton-Rogers, 1995).

Because the current study was highly exploratory, it had no ex ante expectations as to the number or types of viewpoints that may exist about entrepreneurship in the regional culture of Southern Ontario. So, the sampling aimed to obtain high diversity on a range of demographic variables (age, gender, education, income, religion, employment status, and experience as an entrepreneur), in the expectation that this would result in equally high diversity of viewpoints held. On this basis, a sample P set of 43 respondents diverse in these demographic variables was obtained in the greater Toronto area of Southern Ontario.

The next step of $\mathrm{Q}$ methodology is to have each respondent produce their rank ordering of the statements of the $\mathrm{Q}$ set, referred to as a "Q sort." Respondents are given the deck of statement cards and asked to sort them according to their degree of agreement/disagreement with the opinion stated on each card. The ranked cards are sorted onto a template that forces a quasi-normal distribution. Where the respondent opinions are expected to be strong and well-articulated, the distribution template is given a low kurtosis to provide room for subtle disagreements. But where respondent opinions are expected to be less controversial or respondents are expected to be less engaged, a higher kurtosis is used to leave more room for ambiguity and error. The sorting process is an ipsative technique that categorizes the statements in ways that are operant functional distinctions and not merely logical categorizations.

Figure 1 shows the Q-sorting template that was used for this study, ready to receive the ranked cards of a respondent's $Q$ set. The numbers at the top of each column in the template represent weights that are given to the cards that are sorted into that

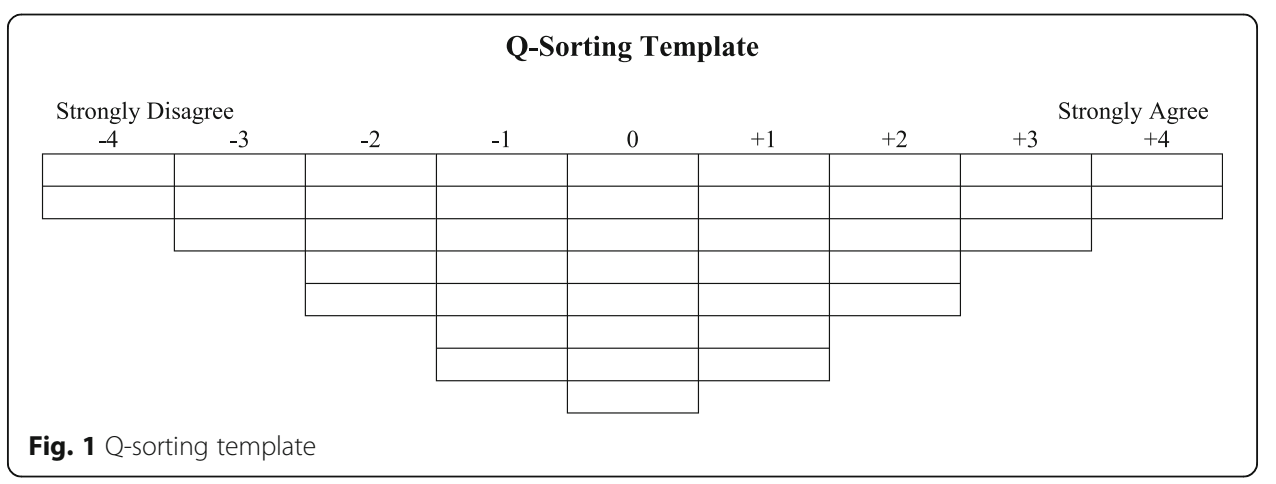


column by the respondent. These weights are the quantitative data that permit the factor analysis aspect of the Q methodology.

Two methods of performing the rank ordering were offered to respondents, according to their preference. Respondents could sort physical cards onto a physical table-top template, or they could use an online simulator created using FlashQ software running in a web browser. In both cases, respondents were permitted to rearrange cards repeatedly until they were satisfied that the Q sort adequately represented their own personal views about entrepreneurship.

The desired characteristic of every Q sort is a consistency in representing the respondent's sentiment, which should represent a holistic expression of their subjective experience or perspective, as far as it is possible to express with the $\mathrm{Q}$ set available to them. Because this Q-sorting operation is wholly subjective, questions of "validity" are of less import, as there is no external criterion by which to make an appraisal. Instead, the Q-sorting process ensures that the factors that subsequently emerge represent categories of operant subjectivity within the culture being studied.

Finally, to capture the qualitative aspects of a respondent's viewpoint, they were also asked to provide textual reasons for the two highest-ranked and two lowest-ranked ("characterizing") statements that they felt most strongly about. These reasons provided additional sources of insight into the correct interpretation of the factors that emerged from the subsequent data analysis.

\section{Analysis technique}

The unique viewpoint of each respondent in the P set is represented by a unique Q sort and the supporting textual reasons they provided. The column weighting information from all of the $\mathrm{Q}$ sorts is $\mathrm{Q}$ factor analysed to reduce the data in a manner that facilitates insight. The " $Q$ " naming of the methodology derives from the observation that this factor analysis is done in a manner orthogonal to the more common " $R$ " factor analyses used in very many empirical research studies. While $\mathrm{R}$ factor analyses attempt to group questions (columns) into emergent constructs that are shared across many respondents, Q factor analysis attempts to group respondents (rows) into emergent viewpoints that are common across many statements of the $\mathrm{Q}$ set. Because of this orthogonal relationship, it is possible to perform Q factor analysis in most statistical software packages by first inverting the data matrix. But in the present study, specialized software (PCQ) was used to extract the Q factors or "viewpoints."

$\mathrm{Q}$ factor analysis uses centroids to extract factors (rather than PCA) because Q starts from a premise of indeterminacy, trying to explore and discover any inherent structure expressed through the $\mathrm{Q}$ sorts. Compared to the unique solution that results from PCA, centroid extraction yields several mathematical solutions from which researchers can select the one that yields the most insight. Factor solutions are usually also rotated to yield this improved insight. These rotations may be judgmental (informed by theory) or varimax (more purely exploratory) (McKeown \& Thomas, 1988). In the present study, lacking any a priori theory of culture and entrepreneurship, the extracted factors were rotated using varimax to produce the maximum clarity and factor differentiation.

The selection of which solution (how many centroids to extract) is usually done on an iterative basis, relying on the researcher's judgement. Solutions are produced for 
different numbers of centroids (typically ranging from 2 to 9). From these, a single solution is selected that maximizes both the number of respondents accounted for in the factors (respondents are not confounded onto multiple factors) to retain the most information and the number of statements that have significant loading onto different factors to yield the most insight into differences between factors. In practice, the retained factors should each have more than one statement loading onto them and should have more than one respondent accounted for by them.

The information of these emergent $\mathrm{Q}$ factors is then supplemented with the qualitative data collected from the characterizing statements of the respondents that correspond to each factor. These respondent verbata are used to suggest or confirm researcher interpretation of the viewpoint underlying each factor. Researchers proposing an interpretation draw upon any statement weights that are shared across all factors (representing a consensus view in the culture) and any statement weights that are significant only to some of the factors (representing viewpoints that are unique to subsets of the culture). From all of this, each emergent viewpoint can be given a descriptive label.

\section{Results}

The data for the present study comprised Q sorts and characterizing statements from the respondents. The resulting Q sort weights were imported into PCQ software for factor analysis. This analysis was iterated by varying the number of centroids, checking for the explanatory power and robustness in the choice of solution. A four-centroid solution was ultimately selected as having the best trade-off between the variance explained and the interpretability of the resulting factors (typically, solutions that account for the data of greater numbers of individual respondents unfortunately provide fewer statements that clearly differentiate between the extracted factors). The chosen solution extracted three orthogonal factors. The emergence of three factors is robust to changes in the number of centroids, up to six, but the number of significant statements describing the factors drops quickly for higher numbers of centroids. Under the selected solution, the factors share nine significant consensus statements that are common across the culture and have 15 significant differentiating statements that distinguish between them.

Data from all 43 respondents were used in extracting the three factors. Of these, the first factor alone accounts for 15 respondents, the second for three respondents, and the third for five respondents. The 20 remaining respondents were cross-loaded between factors (meaning that their views comprised some combination of the canonical viewpoints represented by the individual factors).

The viewpoints of the three extracted factors are represented by the diagram of Fig. 2 which show the "typal" Q sorts of idealized individuals who hold these three viewpoints purely. Each typal Q sort corresponds to a unique subjective perspective that exists in the current of discourse operating in the culture.

\section{Typal subjectivities}

It is worth first noting that there are some common perspectives about entrepreneurship that were shared across all three of the emergent viewpoints in the culture. In 


\section{Typal Q Sorts for Each Viewpoint}

\section{Value Creators}

Strongly Disagree

\begin{tabular}{|c|c|c|c|c|c|c|c|c|}
\hline \multicolumn{8}{|c|}{ Strongly Disagree } & Strongly Agree \\
\hline-4 & -3 & -2 & -1 & 0 & +1 & +2 & +3 & +4 \\
\hline 5 & 9 & 4 & 1 & 20 & 2 & 3 & 13 & 31 \\
\hline 38 & 15 & 6 & 17 & 22 & 7 & 14 & 34 & 33 \\
\hline & 37 & 10 & 18 & 24 & 8 & 19 & 36 & \\
\hline & & 16 & 25 & 26 & 11 & 21 & & \\
\hline & & 39 & 28 & 27 & 12 & 23 & & \\
\hline & & & 29 & 30 & 35 & & & \\
\hline & & & 41 & 32 & 40 & & & \\
\hline & & & & 42 & & & & \\
\hline
\end{tabular}

Gamblers

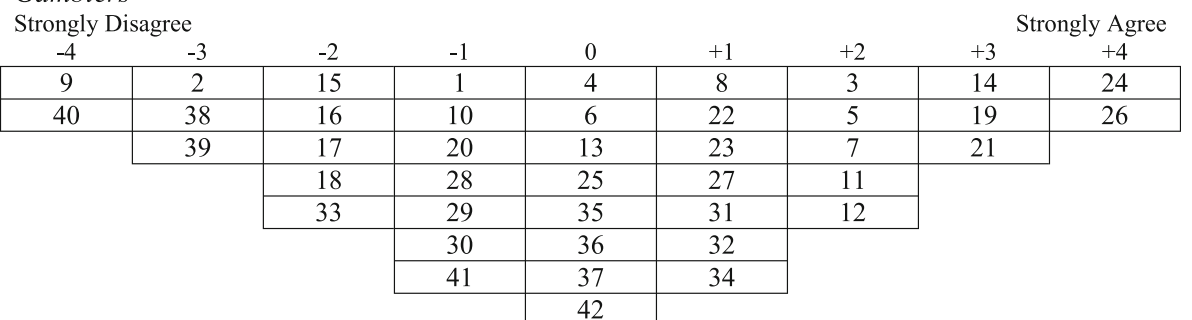

Social Misfits

\begin{tabular}{|c|c|c|c|c|c|c|c|c|}
\hline \multicolumn{8}{|c|}{ Strongly Disagree } & Strongly Agree \\
\hline-4 & -3 & -2 & -1 & 0 & +1 & +2 & +3 & +4 \\
\hline 11 & 8 & 7 & 3 & 4 & 12 & 5 & 1 & 2 \\
\hline 34 & 31 & 18 & 17 & 6 & 13 & 9 & 15 & 25 \\
\hline & 40 & 24 & 19 & 10 & 23 & 16 & 38 & \\
\hline & & 35 & 27 & 14 & 26 & 20 & & \\
\hline & & 36 & 28 & 21 & 29 & 37 & & \\
\hline & & & 30 & 22 & 39 & & & \\
\hline & & & 32 & 33 & 42 & & & \\
\hline & & & & 41 & & & & \\
\hline
\end{tabular}

Fig. 2 Typal Q sorts for each viewpoint

particular, there were nine consensus statements for which all viewpoints provided equivalent levels of agreement. All three viewpoints shared some agreement with the statements:

- "Entrepreneurs control their own destiny."

- "The purpose of entrepreneurship is personal independence and autonomy."

In the P set, there was no significant current of opinion that disagreed with any of these statements. One respondent characterized their agreement with the second statement by saying "This was one of my top reasons for becoming an entrepreneur. After working in the corporate world for twenty years and watching the political games, I wanted to create something more conducive to happiness."

All the viewpoints also shared a degree of disagreement with the statements:

- "Copying other successful businesses is a good idea."

- "You must be very lucky to succeed as an entrepreneur."

- "You need to have a lot of money before you can start a new business."

There was no significant current of opinion in the P set that agreed with either of these statements. One respondent illustrated their disagreement with the role of luck 
by saying "It's not about luck - it's about work, good planning, ideas, and communication."

And finally, all the viewpoints shared a general indifference to the statements:

- "The purpose of entrepreneurship is to create jobs."

- "It is a good idea to use the money of other people (investors) to start your business."

- "It is a bad thing when entrepreneurs destroy an old type of business or traditional way of doing business."

- "Anyone can move up in society by being more entrepreneurial."

This is to say, there were no currents of opinion anywhere in the $\mathrm{P}$ set that either strongly agreed with or strongly disagreed with these statements.

\section{Value creators}

The first subjective viewpoint that emerged was that of people who believe entrepreneurs are primarily agents of value creation-entrepreneurs focus on spotting problems or unmet needs in the marketplace, and on developing products or services that solve these problems or meet these needs. Fifteen respondents were clearly identified as holding this viewpoint alone.

There were three statements that distinguished the subjective perspective of this viewpoint from the others:

- Respondents agreed strongly with the statement "The most important thing for starting a business is to invent a useful new product or service," unlike the mild disagreement of the respondents having other viewpoints.

- They also mildly agreed with the statement "Entrepreneurs must be prepared to challenge the existing social structures," unlike the strong disagreement of the respondents having other viewpoints.

- And they strongly disagreed with the statement "Entrepreneurs are unreasonable people who do not respect social rules," unlike the mild agreement of the respondents having other viewpoints.

The first defining characteristic of this subjective viewpoint is the strong belief in the value proposition delivered by entrepreneurs. People holding the viewpoint believe that entrepreneurs actively seek out unmet needs and then try to develop solutions to meet these. The second defining characteristic is the belief that the potentially disruptive actions of entrepreneurs are justified by this desire to find and solve problems. Entrepreneurs, while perhaps somewhat disruptive, are not unreasonable in trying to change society for the better. Consequently, their activities should be tolerated and supported by society-including a degree of forgiveness for their occasional failures.

Taken together, these results suggest an approving viewpoint in which entrepreneurs are perceived as empowered agents of positive change and social and economic renewal, whose benefits outweigh the modest externalities they impose on society. 


\section{Gamblers}

The second subjective viewpoint was that of people who believe that entrepreneurs are people who deserve to be rewarded for their willingness to take risks and gambles that other people would not take. Three respondents were clearly identified as holding this viewpoint alone.

There were two statements that distinguished the subjective perspective of this viewpoint from the others:

- Respondents agreed strongly with the statement "Entrepreneurs deserve to be rewarded for trying risky new things," unlike the mild disagreement of the respondents having other viewpoints. One respondent specifically remarked that "The majority shy away from risk, so entrepreneurs must be rewarded."

- And they disagreed with the statement "Some people and cultures are just more entrepreneurial than others," unlike the general agreement of the respondents having other viewpoints.

The first defining characteristic of this subjective viewpoint is the emphasis on risktaking propensity and its justification on the basis of results achieved. People holding the viewpoint believe that entrepreneurs take more risks than non-entrepreneurs and that the ends they achieve justify whatever means they may have had to employ in order to reach them. These respondents believe entrepreneurs are therefore deserving of correspondingly large rewards. The second defining characteristic of this viewpoint is the belief that the means employed by entrepreneurs when taking these gambles are limited to socially approved ones. Entrepreneurs may be disruptive challengers of society, but they play fairly within the rules and norms, without resorting to cheating or trickery to ensure their gambles pay off.

Taken together, these results suggest a neutral viewpoint in which entrepreneurs are perceived as gamblers who earn their individual rewards, whether or not society collectively benefits from their effects.

\section{Social misfits}

The third subjective viewpoint was that of people who believe entrepreneurs are unaccountable troublemakers who exploit others in society. Five respondents were clearly identified as holding this viewpoint alone.

There were ten statements that distinguished the subjective perspective of this viewpoint from the others:

- Respondents strongly agreed with the statement "Entrepreneurs have a lot of freedom because they are not accountable to anyone else," unlike the only mild agreement of the respondents having other viewpoints.

- They agreed with the statement "People who start new businesses and then fail are unreliable and not to be trusted," unlike the strong disagreement of the respondents having other viewpoints. As one respondent put it, "Trial-and-error is one thing. However, starting a business and failing is a really big risk that cannot be taken lightly." 
- They agreed with the statement "Entrepreneurs are aggressive troublemakers who create problems," unlike the general disagreement of the respondents having other viewpoints.

- They agreed with the statement "Some social groups (class, religion, caste, ethnicity, gender) are better suited to become entrepreneurs than others," unlike the mild disagreement of the respondents having other viewpoints.

- They agreed with the statement "You should not trust entrepreneurs, they will try to cheat you," unlike the strong disagreement of the respondents having other viewpoints. It may be that this view is very much affected by personal experience with entrepreneurs. As one respondent said, "This belief comes from a personal experience with an entrepreneur. At first I trusted him, but then I soon found out that I was being ripped off. This has led me to be wary of all entrepreneurial ventures."

- They agreed with the statement "Entrepreneurs exploit the work of others to make themselves rich," unlike the disagreement of the respondents having other viewpoints.

- They disagreed with the statement "The most important thing for starting a business is to spot a big customer need," unlike the general agreement of the respondents having other viewpoints.

- They disagreed with the statement "Entrepreneurs see the world differently than other people," unlike the mild agreement of the respondents having other viewpoints.

- They strongly disagreed with the statement "If you know that something needs to be done in the world, you should do it yourself instead of waiting for someone else to do it," unlike the mild agreement of the respondents having other viewpoints.

- And finally, they strongly disagreed with the statement "The support of friends and family is important when starting a new business," unlike the general agreement of the respondents having other viewpoints.

The first defining characteristic of this subjective viewpoint is that entrepreneurs are a uniquely self-interested and disruptive subset of society, not particularly interested in making society better. People holding the viewpoint believe that entrepreneurs ought to be held to account for the disruptions they cause. The second defining characteristic of this viewpoint is the belief that seeing an unexploited and personally attractive opportunity is not, in itself, sufficient justification for acting upon it. Entrepreneurs should take into consideration the collateral effects of their actions on those around them, in their immediate network, the wider industry context, and the still wider social and cultural context.

Taken together, these results suggest a disapproving viewpoint in which entrepreneurs are perceived as loose cannons, capable of harming others in their pursuit of personal gain, and unfairly shielded from the consequences of their actions.

\section{Discussion}

The respondents who participated in this study have provided a unique and insightful perspective into the beliefs and attitudes that some Canadians hold about entrepreneurship-insights that are not uniform and constant across the whole of Canada's national 
culture. And the novel application of Q methodology to this exploratory effort has demonstrated a valuable means of uncovering these beliefs and attitudes that may have been difficult to discover through other exploratory approaches. Q methodology is unique in that it provides a robust basis for discovering shared subjectivities that integrate abstract macro aspects of culture with specific influences that shape the attitudes of individual people in a society. In the present case, this has shown that the national culture of Canada is not uniform in its influence on the entrepreneurial views of individuals. Even when controlling for possible regional variations in culture, the views and attitudes of Canadians towards entrepreneurship show significant and systematic variations that indicate the existence of intermediated cultural influence.

Table 2 illustrates in greater quantitative detail the nature and extent of the similarities and differences among the three viewpoints. It shows the degree to which people holding each of the typal viewpoints agree with $(+4)$ or disagree with $(-4)$ each of the opinion statements in the Q set.

\section{Conclusions}

The results of this study can be situated between the macro perspective of Hofstede's national cultures and the micro perspective of individual cognition and link the myths and metaphors of a national culture with the subjectivity of individual beliefs and perceptions. The objective aspects of these insights arise through the analytic emergence of intermediate streams of opinion as loadings of respondents onto the discovered factors. And the subjective aspects of these insights arise through the capture of $\mathrm{Q}$ sorts that reflect the various individual meanings that respondents ascribed to entrepreneurial activities. A holistic integration of these perspectives arises from the combination of quantitative and qualitative data to impute interpretations for each of the three viewpoints that emerged. These viewpoints are emergent in that they do not represent any a priori logical categorisation imposed by researchers, but rather reflect the operant similarities and differences actually present in the cultural discourse about entrepreneurship. In the Southern Ontario region of Canada, these viewpoints were the entrepreneur as heroic problem-solver, as indifferent gambler, and as troublesome problem-creator. These results show how a broad national culture, such as may be captured by measures like GLOBE or Hofstede, can become diverse intermediate influences on the individual. Even within the same national and regional cultural context, individuals may find themselves immersed in an intermediated culture that exhibits any of the three viewpoints discovered here and therefore may be subject to widely differing social norms and influences on their individual views and their prospective entrepreneurial activities.

The results of this study clearly support the position that culture has a significant influence on entrepreneurship. But this study further contributes to an understanding that this influence is more nuanced and heterogeneous than previous theories of a monolithic and unclearly defined national culture reflect. Intermediated culture can operate in many different ways.

It therefore appears that the influences of national culture on entrepreneurship found by previous researchers are alone not sufficiently granular to capture the mechanisms by which culture and national systems (Szerb, Acs, \& Autio, 2013) operate to encourage or discourage entrepreneurship. The cultural viewpoints discovered in this present research may play an important role in the effects of national (or regional) culture on the 
Table 2 Q set factor weights

\begin{tabular}{|c|c|c|c|}
\hline Statement summary & Value creators & Gamblers & Social misfits \\
\hline 1. Some groups better suited & -1.0 & 0.3 & -2.2 \\
\hline 2. Some people more entrepreneurial & 0.9 & 1.0 & -2.6 \\
\hline 3. Unique personality type & 1.5 & -0.7 & 1.4 \\
\hline 4. Quantity over quality & -1.3 & 0.0 & 0.0 \\
\hline 5. Unreasonable people & -2.1 & -1.3 & -2.0 \\
\hline 6. Independent rebels & -1.3 & 1.0 & -0.2 \\
\hline 7. Future over present & 0.5 & 0.7 & 1.4 \\
\hline 8. See the world differently & 0.7 & -2.0 & 2.2 \\
\hline 9. Untrustworthy cheaters & -1.9 & 1.3 & -1.8 \\
\hline 10. Unrealistically high opinion & -1.3 & -0.3 & 0.0 \\
\hline 11. Do it yourself & 0.8 & -0.3 & 2.2 \\
\hline 12. Control own destiny & 0.8 & 1.3 & -1.0 \\
\hline 13. Do what others only dream & 1.7 & -1.0 & -0.4 \\
\hline 14. Seek problems & 1.5 & 0 & 0.4 \\
\hline 15. Aggressive troublemakers & -2.1 & -0.3 & -2.2 \\
\hline 16. Exploit others & -2.1 & 0.0 & -1.4 \\
\hline 17. Copy successful businesses & -0.6 & 0.7 & 0.8 \\
\hline 18. Must be lucky & -1.1 & 0.3 & 1.4 \\
\hline 19. Worldview, not small business mgt & 1.1 & -2.0 & 0.8 \\
\hline 20. Make lots of money & 0.2 & 1.7 & -1.8 \\
\hline 21. Satisfy needs of others & 1.3 & -1.0 & 0.4 \\
\hline 22. Create jobs & 0.2 & -0.3 & 0.2 \\
\hline 23. Personal autonomy & 1.5 & -1.7 & -0.4 \\
\hline 24. Risk deserves reward & 0.3 & -3.0 & 1.4 \\
\hline 25. Free, not accountable & -0.6 & -0.7 & -2.4 \\
\hline 26. Ends over means & -0.3 & -2.3 & -0.6 \\
\hline 27. Create your own job & 0.3 & -0.3 & 0.4 \\
\hline 28. Need to have money to start & -0.9 & -0.3 & 0.4 \\
\hline 29. Need connections to start & -1.3 & -0.7 & -1.0 \\
\hline 30. Use investor money & 0.2 & -1.3 & 0.6 \\
\hline 31. Customer need is important & 2.7 & 0.3 & 2.2 \\
\hline 32. Talented partners are important & 0.6 & 1.0 & 1.2 \\
\hline 33. Product is important & 2.8 & 1.0 & -0.4 \\
\hline 34. Social support is important & 2.1 & -0.3 & 2.6 \\
\hline 35. Make society better & 1.3 & 0.3 & 1.4 \\
\hline 36. Generate and spread wealth & 1.7 & 1.0 & 1.4 \\
\hline 37. Divide and disrupt people & -1.9 & 0.7 & -1.4 \\
\hline 38. Failures are untrustworthy & -2.9 & 1.7 & -1.8 \\
\hline 39. Failures have no benefit & -1.9 & 1.3 & -0.4 \\
\hline 40. Must challenge society & 1.2 & 2.0 & 1.8 \\
\hline 41. Creative destruction is bad & -1.1 & 1.7 & 0.2 \\
\hline 42. Social mobility & -0.1 & 0.7 & -0.8 \\
\hline
\end{tabular}


views and attitudes of individuals. As an example, a Canadian individual situated in a local environment dominated by the Social Misfits viewpoint may develop strongly negative subjective norms towards entrepreneurship, even despite the generally favourable attitudes found in the Canadian national culture, and may therefore be strongly inhibited from pursuing entrepreneurship. Similarly, an individual situated in a predominantly Value Creators local environment may be strongly supported in pursuing entrepreneurship, beyond the support inherent in the overall Canadian national culture.

These results suggest a significant opportunity for policy-makers and advisors in the Canadian entrepreneurial ecosystem who desire to promote greater levels of entrepreneurial intention and entrepreneurial prevalence in Canada. While many of past practical efforts in the ecosystem have focused on improving the self-efficacy and attitudes of individuals, attention has only recently turned to the important role of national cultures in encouraging and supporting greater entrepreneurship. But the present results suggest that these efforts should not simply be broad-spectrum approaches to encouraging entrepreneurial culture at national or regional levels. Rather, they should seek to understand the range and prevalence of attitudes present in the ecosystem, and the occupational reward structures they engender (Bonaventura \& Caserta, 2012), which may have a stronger and more direct influence on potential entrepreneurs.

\section{Limitations}

This study has been an initial exploration of the intermediate effects of culture on entrepreneurship in one region of Canada. It is therefore subject to many limitations and caveats. The first is that it has not made any investigation into the proportions in which each of these viewpoints may exist in the general population, or the strength with which these views are held. Nor is it known to be an exhaustive discovery of all the viewpoints that exist in the cultural discourse; other points of view may also be present but as yet uncovered.

It should also be noted that this study measured the strength of agreement respondents had with the statements in the $\mathrm{Q}$ set, but did not attempt to measure the importance they gave to the statements in shaping their overall perceptions of the value of entrepreneurship. Cultural factors are just one of many influences on the beliefs and attitudes that individuals may hold towards entrepreneurship. It may be possible, for example, for an individual to subscribe to the Social Misfits viewpoint in general, yet still support instances of entrepreneurship in specific due to other overriding positive factors that are unique to that instance.

Finally, the limited sample drawn from the Toronto urban area may not be indicative of viewpoints that might exist in other parts of Canada. It is possible that other regional cultures (for example, Quebec, Maritimes, or the West) or specific industrial sectors or regions (for example, high-tech clusters, resource extraction economies) may contain additional viewpoints that exist in the complete Canadian discourse around entrepreneurship.

\section{Future research directions}

From the perspective of the integrated model of EI developed by Siu and Lo (2013), culture could be operating through two different mechanisms. In the first case, culture would be represented in the social norms construct and the direct effects would be 
represented by a unidimensional valency such as the clear approve/neutral/disapprove seen in the three viewpoints. For example, an individual embedded in a local environment where the Value Creator viewpoint is predominant would perceive the social norms to be positive towards entrepreneurial activities and would therefore be more likely to pursue them.

In the second case, culture would be a moderator of the influences that attitudes, social norms, and self-efficacy have upon entrepreneurial activities. Each of the three viewpoints could potentially moderate these relationships independent of the others, since the plurality of respondents were observed to hold views and opinions that were composites of the typal viewpoints. For example, an individual embedded in a local environment where the Value Creator viewpoint is predominant might find the influences of attitudes, social norms and efficacy on entrepreneurship are all strengthened. An individual embedded in a local environment where the Gambler viewpoint is predominant might find the influence of efficacy on entrepreneurship is strengthened, while the influence of attitudes and social norms is weakened. And an individual embedded in a local environment where the Social Misfit viewpoint is predominant might find the influence of attitudes and social norms on entrepreneurship is strengthened, while the influence of efficacy is weakened. The existence and relative influence of these two potential mechanisms is a strong candidate for subsequent research efforts.

In both cases, it is clear that the three cultural viewpoints would affect entrepreneurship in very different ways. This observation highlights the important contribution that is made by discovering the existence of intermediate culture and of considering its effects separately when theorizing about the broader relationship between culture and entrepreneurship. Future research into intermediate effects of culture should particularly seek to address the limitations of this study with a more robust Q study to confirm the stability and completeness of the identified viewpoints, followed by a larger-scale representative survey using a randomized sample and quantitatively validated new measures of respondent viewpoint (Danielson, 2009). A broader replication of this type would need to control for other sources of variance, such as region, language, urban/rural, or ethnicity. And future entrepreneurship research that aims to include culture as an antecedent factor should aim to operationalize it at the intermediate level identified here, rather than as a monolithic national culture.

Acknowledgements

Not applicable.

Authors' contributions

The author read and approved the final manuscript.

Funding

Not applicable.

Availability of data and materials

The datasets used and analysed during this study are available from the corresponding author on reasonable request.

Competing interests

The author declares that he has no competing interests.

Received: 20 February 2019 Accepted: 9 July 2019

Published online: 22 July 2019 
Anderson, A. R. (2005). Enacted metaphor: The theatricality of the entrepreneurial process. International Small Business Journal, 23(6), 587-603.

Anderson, A. R., Drakopoulou-Dodd, S., \& Scott, M. G. (2000). Religion as an environmental influence on enterprise culture. International Journal of Entrepreneurial Behaviour \& Research, 6(1), 5-20.

Anderson, A. R., \& Warren, L. (2011). The entrepreneur as hero and jester: Enacting the entrepreneurial discourse. International Small Business Journal, 29(6), 589-609.

Armington, C., \& Acs, Z. J. (2002). The determinants of regional variation in new firm formation. Regional Studies, 36(1), 33-45.

Autio, E., Pathak, S., \& Wennberg, K. (2013). Consequences of cultural practices for entrepreneurial behaviors. Journal of International Business Studies, 44, 334-362.

Babcock-Lumish, T. L. (2005). Venture capital decision-making and the cultures of risk: An application of Q methodology to US and UK innovation clusters. Competition \& Change, 9(4), 329-356.

Balaku, M. M., Kikooma, J. F., Bantu, E., Onderi, P., \& Otto, K. (2019). Impact of personal cultural orientations and cultural intelligence on subjective success in self-employment in multi-ethnic societies. Journal of Global Entrepreneurship Research, 9(1), art 8.

Barazandeh, M., Parvizian, K., Alizadeh, M., \& Khosravi, S. (2015). Investigating the effect of entrepreneurial competencies on business performance among early stage entrepreneurs global Entreprneeurp monitor (GEM 2010 survey data). Journal of Global Entrepreneurship Research, 5(8), 1-12.

Baum, J. A. C., \& Oliver, C. (1991). Institutional linkages and organizational mortality. Administrative Science Quarterly, $36(2), 187-218$

Bernardo, A. E., \& Welch, I. (2001). On the evolution of overconfidence and entrepreneurs. Journal of Economics and Management Strategy, 10(3), 301-330.

Bonaventura, L., \& Caserta, M. (2012). The social dimension of entrepreneurship: The role of regional social effects. Entrepreneurship Research Journal, 2(3), 1-16.

Brown, S. R. (1980). Political subjectivity: Applications of Q methodology in political science. New Haven: Yale University Press.

Brown, S. R. (1993). A primer on Q methodology. Operant Subjectivity, 16(3/4), 91-138.

Cardon, M. S., Zietsma, C., Saparito, P., Matherne, B. P., \& Davis, C. (2004). A tale of passion: New insights into entrepreneurship from a parenthood metaphor. Journal of Business Venturing, 20, 23-34.

Carr, J. C., \& Sequeira, J. M. (2007). Prior family business exposure as intergenerational influence and entrepreneurial intent: A theory of planned behavior approach. Journal of Business Research, 60(10), 1090-1098.

Chang, C. C. (2012). Exploring IT entrepreneurs' dynamic capabilities using Q-technique. Industrial Management \& Data Systems, 112(8), 1201-1216.

Chrisman, J. J., Chua, J. H., \& Steier, L. P. (2002). The influence of national culture and family involvement on entrepreneurial perceptions and performance at the state level. Entrepreneurship Theory \& Practice, 26(4), 113-130.

Chu, P. (1996). Social network models of overseas Chinese entrepreneurship: The experience in Hong Kong and Canada. Canadian Journal of Administrative Sciences, 13(4), 358-365.

Danielson, S. (2009). Q method and surveys: Three ways to combine Q and R. Field Methods, 21(3), 219-237.

Davidsson, P. (1995). Culture, structure and regional levels of entrepreneurship. Entrepreneurship \& Regional Development, 7(1), 41-62.

Davis, C. (1988). Science, technology and policy in Quebec. Science and Public Policy, 15(1), 26-34.

Davis, C., Valliere, D., Lin, H., \& Wolff, N. (2014). Driving wealth creation \& social development in Ontario: The 2013 Ontario GEM report. Toronto: Ryerson University.

De Mol, J., \& Buysse, A. (2008). Understandings of children's influence in parent child relationships: A Q-methological study. Journal of Social and Personal Relationships, 25, 359-379.

DiMaggio, P. J., \& Powell, W. W. (1983). The iron cage revisited: Institutional isomorphism and collective rationality in organizational fields. American Sociological Review, 48, 147-160.

Drakopoulou-Dodd, S. (2002). Metaphor and meaning: A grounded cultural model of US entrepreneurship. Journal of Business Venturing, $17(5), 519-535$.

Drennan, J., Kennedy, J., \& Renfrow, P. (2005). Impact of childhood experience on the development of entrepreneurial intention. International Journal of Entrepreneurship and Innovation, 6(4), 231-238.

Durning, D. W., \& Brown, S. R. (2007). Q methodology and decision making. In G. Morcol (Ed.), Handbook of decision making. CRC: New York.

Dzopia, F., \& Ahern, L. (2011). A systematic literature review of the applications of Q-technique and its methodology. Methodology, 7(2), 39-55.

Gatewood, E. J., Shaver, K. G., \& Gartner, W. B. (1995). A longitudinal study of cognitive factors influencing start-up behaviors and success at venture creation. Journal of Business Venturing, 10(5), 371-391.

Giddens, A. (1971). Capitalism and modern social theory: An analysis of the writings of Marx, Durkheim and Max Weber. Cambridge: Cambridge University Press.

Grunhagen, M., \& Volkmann, C. K. (2014). Antecedents of academics' entrepreneurial intentions: Developing a peopleoriented model for university entrepreneurship. International Journal of Entrepreneurial Venturing, 6(2), 179-200.

Gustafson, B., Hanley, M., \& Popovich, M. (2008). Women's perceptions of female body shapes and celebrity models: The dove firming cream advertising revisited. San Mateo: Paper presented at the Conference of The American Academy of Advertising.

Hayton, J. C., George, G., \& Zahra, S. A. (2002). National culture and entrepreneurship: A review of behavioral research. Entrepreneurship Theory \& Practice, 26(4), 33-52.

Heilbrunn, S., Itzkovitch, Y., \& Weinberg, C. (2017). Perceived feasibility and desirability of entrepreneurship in institutional contexts in transition. Entrepreneurship Research Journal, 7(4), 785-796.

Hermans, F., Kok, K., Beers, P. J., \& Veldkamp, T. (2012). Assessing sustainability perspectives in rural innovation projects using Q-methodology. Sociologia Ruralis, 52(1), 70-91.

Higgins, E. T. (2008). Culture and personality: Variability across universal motives as the missing link. Social and Personality Psychology Compass, 2(2), 608-634.

Hofstede, G. (1980). Culture's consequences: International differences in work-related values. Beverly Hills: Sage Publications.

Hofstede, G., Hofstede, G. J., Minkov, M., \& Vinken, H. (2008). Values survey module 2008. Velp: Geert Hofstede BV. 
House, R., Javidan, M., \& Dorfman, P. (2001). Project GLOBE: An introduction. Applied Psychology: An International Review, 50(4), 489-505.

Huggins, R., \& Thompson, P. (2012). Entrepreneurship and community culture: A place-based study of their interdependency. Entrepreneurship Research Journal, 2(1), 1-34.

Hyrsky, K. (1999). Entrepreneurial metaphors and concepts: An exploratory study. International Small Business Journal, 18(1), 13-34.

Ibrahim, O. A., Devesh, S., \& Ubaibullah, V. (2017). Implications of attitude of graduate students in Oman towards entrepreneurship: An empirical study. Journal of Global Entrepreneurship Research, 7(4), 1-17.

Janson, C., Militello, M., \& Kosine, N. (2008). Four views of the professional school counsellor principle relationship: A Qmethodology study. Professional School Counselling, 11, 353-361.

Kauppinen, A. (2017). Entrepreneurial identity construction and consumption of cultural products (movies). International Journal of Entrepreneurial Venturing, 9(4), 315-345.

Langford, C. H., Josty, P., \& Holbrook, J. A. (2013). Driving wealth creation \& social development in Canada. Calgary: The Centre for Innovation Studies.

Lee, B. S., \& Synn, W. (2001). Investor response to online stock trading: A study using Q methodology. Operant Subjectivity, 24(3), 109-131.

Lehman, T., \& Young, T. R. (1974). From conflict theory to conflict methodology: An emerging paradigm for sociology. Sociological Inquiry, 44(1), 15-28.

Liñán, F., \& Chen, Y. W. (2009). Development and cross-cultural application of a specific instrument to measure entrepreneurial intentions. Entrepreneurship Theory \& Practice, 33(3), 593-617.

Lyons, T. S., Alter, T. R., Audretsch, D. B., \& Augustine, D. (2012). Entrepreneurship and community: The next frontier of entrepreneurship inquiry. Entrepreneurship Research Journal, 2(1), 1-24.

Maclntosh, N. B., \& Scapens, R. W. (1990). Structuration theory in management accounting. Accounting Organizations and Society, 15(5), 455-477.

McGrath, R. G., MacMillan, I. C., \& Scheinberg, S. (1992). Elitists, risk-takers, and rugged individualists? An exploratory analysis of cultural differences between entrepreneurs and non-entrepreneurs. Journal of Business Venturing, 7(2), 441-458.

McKeown, M., \& Thomas, D. (1988). Q-methodology. Newbury Park: Sage.

Michelle, C., \& Davis, C. (2014). Beyond the qualitative/quantitative "divide": Reflections on the utility and challenges of Q methodology for media researchers. In A. N. Valdivia \& F. Darling-Wolf (Eds.), The international encyclopedia of media studies (Vol. VII). New York: Wiley.

Morris, M. H., Avila, R. A., \& Allen, J. (1993). Individualism and the modern corporation: Implications of innovation and entrepreneurship. Journal of Management, 19(3), 595-612.

Nicholson, L., \& Anderson, A. (2005). News and nuances of the entrepreneurial myth and metaphor: Linguistic games in entrepreneurial sense-making and sense-giving. Entrepreneurship Theory and Practice, 29(2), 153-172.

North, D. C. (1991). Institutions. Journal of Economic Perspectives, 5(1), 97-112.

Ockwell, D. G. (2008). 'Opening up' policy to reflective appraisal: A role for Q methodology? A case study of fire management in Cape York. Australia Policy Science, 41, 263-292.

Ogunsade, I. A., \& Obembe, D. (2016). The influence of informal institutions on informal sector entrepreneurship: A study of Nigeria's hand-woven textile industry. Journal of Small Business and Entrepreneurship, 28(6), 413-429.

Palich, L. E., \& Bagby, D. R. (1995). Using cognitive theory to explain entrepreneurial risk-taking: Challenging conventional wisdom. Journal of Business Venturing, 10(6), 425-438.

Peterman, N. E., \& Kennedy, J. (2003). Enterprise education: Influencing students' perceptions of entrepreneurship. Entrepreneurship Theory \& Practice, 28, 129-144.

Pinillos, M. J., \& Reyes, R. (2011). Relationship between individualist-collectivist culture and entrepreneurial activitiy: Evidence from Global Entrepreneurship Monitor data. Small Business Economics, 37(1), 23-37.

Pitt, M. (1998). A tale of two gladiators: 'Reading' entrepreneurs as texts. Organization Studies, 19(3), 387-413.

Rocha, H. O., \& Sternberg, R. (2005). Entrepreneurship: The role of clusters theoretical perspectives and empirical evidence from Germany. Small Business Economics, 24(3), 267-292.

Schlaegel, C., Engle, R. L., Dimitriadi, N., \& Taureck, P. C. (2015). Why not now?': Triggers and barriers of new venture creation: A meta-analysis and multinational comparison of entrepreneurs' perspectives. International Journal of Entrepreneurial Venturing, 7(3), 227-250.

Schlaegel, C., \& Koenig, M. (2014). Determinants of entrepreneurial intent: A meta-analytic test and integration of competing models. Entrepreneurship Theory \& Practice, 38(2), 291-332.

Semerci, A. B., \& Cimen, M. (2017). Environmental incentives of entrepreneurship: Fuzzy clustering approach to OECD countries. Journal of Global Entrepreneurship Research, 7(12), 1-19.

Shapero, A., \& Sokol, L. (1982). Social dimensions of entrepreneurship. In C. Kent, D. Sexton, \& K. Vesper (Eds.), The encyclopedia of entrepreneurship (pp. 72-90). Englewood Cliffs: Prentice-Hall.

Simon, M., Houghton, S. M., \& Aquino, K. (1999). Cognitive biases, risk perception, and venture formation: How individuals decide to start companies. Journal of Business Venturing, 15(2), 113-134.

Siu, W. S., \& Lo, E. S. (2013). Cultural contingency in the cognitive model of entrepreneurial intention. Entrepreneurship Theory \& Practice, 37(2), 147-173.

Stainton-Rogers, W. (1995). Q-methodology. In J. Smith, R. Harre, \& L. Van Langenhove (Eds.), Rethinking methods in psychology. New York: Sage.

Stenner, P., Watts, S., \& Worrell, M. (2008). Q methodology. In C. Willig \& W. Stainton-Rogers (Eds.), The sage handbook of qualitative research in psychology (pp. 215-239). Los Angeles: Sage.

Stephenson, W. (1935). Correlating persons instead of tests. Character and Personality, 4(1), 17-24.

Stephenson, W. (1953). The study of behavior: Q-technique and its methodology. Chicago: University of Chicago Press.

Swierczek, F. W., \& Ha, T. T. (2003). Entrepreneurial orientation, uncertainty avoidance and firm performance: An analysis of Thai and Vietnamese SMEs. International Journal of Entrepreneurship and Innovation, 4(1), 46-58.

Szerb, L. A., Acs, Z., \& Autio, E. (2013). Entrepreneurship and policy: The National System of Entrepreneurship in the European Union and in its member countries. Entrepreneurship Research Journal, 3(1), 9-34. 
Urban, B., \& Ratsimanetrimanana, F. A. (2015). Culture and entrepreneurial intention of Madagascan ethnic groups. Journal of Entrepreneurship in Emerging Economies, 7(2), 86-114.

Valliere, D. (2015). Entrepreneurial sensegiving and the attention contract. The International Entrepreneurship and Management Journal, 11(1), 77-94.

Valliere, D., \& Gegenhuber, T. (2014). Entrepreneurial remixing: Bricolage and postmodern resources. International Journal of Entrepreneurship and Innovation, 15(1), 39-49.

Valliere, D., \& Peterson, R. (2009). Entrepreneurship and economic growth: Evidence from emerging and developed countries. Entrepreneurship \& Regional Development, 21(5/6), 459-480.

Watts, S., \& Stenner, P. (2005). Doing Q methodology: Theory, method and interpretation. Qualitative Research in Psychology, 2(1), 67-91.

Weber, M. (1905). The Protestant ethic and the spirit of capitalism (L. Lacambra, trans.). Los Angeles, Roxbury (1998).

Wong, P. K., Ho, Y. P., \& Autio, E. (2005). Entrepreneurship, innovation and economic growth: Evidence from GEM data. Small Business Economics, 24, 335-350.

Zhang, P., Wang, D. D., \& Owen, C. L. (2015). A study of entrepreneurial intention of university students. Entrepreneurship Research Journal, 5(1), 61-82.

Zhao, H., Seibert, S. E., \& Lumpkin, G. T. (2010). The relationship of personality to entrepreneurial intentions and performance: A meta-analytic review. Journal of Management, 36(2), 381-404.

\section{Publisher's Note}

Springer Nature remains neutral with regard to jurisdictional claims in published maps and institutional affiliations.

Submit your manuscript to a SpringerOpen ${ }^{\odot}$ journal and benefit from:

- Convenient online submission

Rigorous peer review

- Open access: articles freely available online

- High visibility within the field

- Retaining the copyright to your article

Submit your next manuscript at $\boldsymbol{\nabla}$ springeropen.com 